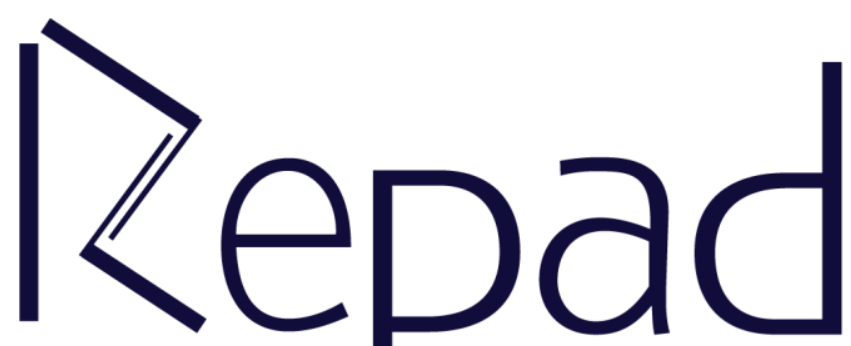

v. 4, n. 2, Maio-Agosto/2020

Revista Estudos e

Pesquisas em Administração 


\title{
MARKETING DIGITAL E COMPORTAMENTO DO CONSUMIDOR: Evidências no mercado de varejo de vestuário de Cuiabá-MT
}

Marcos Júnior de Figueiredo Silva marcosfigueiredo19@gmail.com https://orcid.org/0000-0002-6743-5661 Universidade Federal de Mato Grosso Cuiabá-Mato Grosso, Brasil

Francisco Mirialdo Chaves Trigueiro http:/orcid.org/0000-0002-4704-2764 Universidade Federal de Mato Grosso Cuiabá-Mato Grosso, Brasil

Fernando Thiago https://orcid.org/0000-0002-7947-0667 Universidade Federal de Mato Grosso do Sul Corumbá-Mato Grosso do Sul, Brasil

\section{Resumo}

Com a mudança nas relações sociais e o surgimento de novos canais de interações, passou a ser uma necessidade para as empresas conhecer o comportamento deste novo consumidor altamente conectado, e assim, conhecer as influências que levam a comprar determinado produto. O marketing digital apresenta-se como uma nova maneira de interação da empresa informar seu consumidor sobre seu produto, por meio de diversas ações, tais como, marketing de conteúdo, marketing de mídias sociais e ferramentas de monitoramento e segmentação. Dessa forma, o presente estudo tem por objetivo foi descrever as estratégias de marketing digital utilizadas pelas empresas do varejo de vestuário de Cuiabá-MT e o perfil e comportamento dos consumidores desta região. Para tanto, foi realizada uma pesquisa mista a partir de três entrevistas, sendo duas com gestores de lojas do segmento estudado e uma com um especialista do assunto, e realizado um levantamento (survey) junto aos consumidores da região estudada. Os principais resultados mostram que os consumidores em sua maioria não são influenciados por ações de marketing digital, porém, as empresas reconhecem a importância deste para que o cliente a encontre, destacando a criação de relacionamentos.

Palavras-chave: Comportamento do consumidor; Influências de compra; Marketing Digital; Varejo de vestuário.

\section{DIGITAL MARKETING AND CONSUMER BEHAVIOR: Evidence in the retail market in Cuiaba-MT}

\begin{abstract}
With the change in social relations and the emergence of new channels of interactions, it became a necessity for companies to know the behavior of this new highly connected consumer, and thus, to know the influences that lead to buy a certain product. Digital marketing presents itself as a new way of interaction for the company to inform its
\end{abstract}


consumer about its product, through various actions, such as content marketing, social media marketing and monitoring and segmentation tools. Thus, this study aims to describe the digital marketing strategies used by clothing retail companies in Cuiabá/Brazil and the profile and behavior of consumers in this region. To this end, a mixed survey was conducted based on three interviews, two with store managers in the segment studied and one with an expert on the subject, and a survey was carried out with consumers in the region studied. The main results show that consumers are mostly not influenced by digital marketing actions, however, companies recognize the importance of this for the customer to find it, highlighting the creation of relationships.

Keywords: Consumer behavior; Influences of purchase; Digital marketing; Retail clothing.

Submetido: $18 / 03 / 2020$

Aceito: 05/05/2020

Publicado: 31/05/2020

\section{Introdução}

A mudança constante nas relações sociais proporcionou um grande desafio para os profissionais da atualidade, com destaque para entender como se dão as novas formas de interação social. Com a revolução da Internet a partir dos anos 2000, e o início da era da informação, causando a acessibilidade de informações, criação de conteúdo, novos meios de interação e comunicação, foi necessário que o marketing também evoluísse junto com seu público-alvo. Diante destes acontecimentos, torna-se necessário que as empresas acompanhem a evolução e as mudanças causadas por esta era para assim poder antecipar seus concorrentes, entender seu cliente e saber o que o consumidor espera, para assim atingir melhores resultados.

$\mathrm{Na}$ era digital o consumidor assume outro papel: o de influenciador de decisões, uma vez que a publicação de opiniões em redes sociais e outras plataformas ajudam a construir ou destruir uma empresa. $\mathrm{O}$ consumidor desta era pesquisa sobre o produto ou serviço antes de comprar, buscando informações e experiências de outros consumidores, nas plataformas e mídias sociais (TORRES, 2009).

No Brasil, pouco mais de 146 milhões de pessoas estão conectadas à Internet, segundo dados do IBGE (Instituto Brasileiro de Geografia e Estatística), então, as empresas devem conhecer e entender como se dão essas novas formas de interação e o consumidor, principalmente no ambiente virtual, que atualmente, é o meio mais utilizado de interação social (IBGE, 2018). A partir desta perspectiva, o marketing foi moldado do tradicional ao digital, tendo um foco maior no relacionamento com os consumidores.

Segundo Torres (2009), para melhor eficiência do marketing digital, devem ser utilizadas seis ferramentas estratégicas, sendo elas: marketing de conteúdo, marketing de mídias sociais, marketing viral, e-mail marketing, pesquisa on-line, publicidade online e monitoramento. Dentro desta perspectiva, a empresa deve utilizar de blogs para criação de conteúdo e interação, redes sociais e site da empresa, como meio de relacionamento e publicidade, e-mails e outras mensagens de texto para o marketing direto. Esta evolução afetou diversos setores, inclusive o de varejo de vestuário, que navegando pela Internet, não é tão difícil perceber a quantidade de empresas que utilizam destas ações para ter maior relacionamento e visibilidade de seu produto. 
Do exposto, levanta-se a seguinte questão-problema desse estudo: como o marketing digital é trabalhado por empresas de vestuário e qual é o comportamento de compra dos consumidores deste setor em Cuiabá-MT? O objetivo da pesquisa foi descrever as estratégias de marketing digital utilizadas pelas empresas do varejo de vestuário de Cuiabá-MT e o perfil e comportamento dos consumidores desta região.

A mudança de perfil do consumidor, ocasionado pela evolução da tecnologia, faz com que seja um novo desafio aos profissionais da administração entender este novo consumidor, como ele se relaciona, e o que influencia na sua compra, para buscar soluções e estratégias de marketing para se aproximar deste consumidor. A partir deste contexto exposto, este estudo se justifica em três vertentes: científica, social e econômica. Do ponto de vista econômico, as empresas e profissionais da área podem utilizar das informações contidas no estudo para aplicar e traçar ações e estratégias de marketing digital ou tradicional. Do ponto de vista social, possibilitará que o consumidor entenda quais estratégias utilizadas pelas empresas e seu papel como influenciador de decisões. E científico, pois pode servir de base para outros estudos em segmentos diversos, ou regiões.

\section{Fundamentação Teórica}

\subsection{Transição do marketing tradicional 1.0 ao marketing digital 4.0}

$\mathrm{O}$ marketing passou por várias transformações se moldando de acordo com a evolução da sociedade. Kotler e Keller (2012, p. 4) definem que "marketing é um processo social pelo qual indivíduos e grupos obtêm o que necessitam e desejam por meio da criação, da oferta e da livre troca de produtos de valor entre si”'. Para os autores a tarefa do marketing consiste na identificação e satisfação das necessidades humanas e sociais, gerando lucro para as organizações. Sendo assim, o objetivo do marketing é conhecer e entender o cliente tão bem para que chegue ao ponto do produto ou serviço se vender sozinho.

Segundo Kotler, Kartajaya e Setiawan (2012), as mudanças na macroeconomia são propulsoras da mudança no marketing, uma vez que essas mudanças ocasionadas pela macroeconomia afetam diretamente no comportamento dos consumidores. Em consonância com a visão de Kotler, Kartajaya e Setiawan (2012), o conceito de marketing foi se moldando de acordo com a alteração da sociedade. Percebe-se na evolução do marketing e da sociedade que as estratégias utilizadas no marketing tradicional, por si só, não bastavam para uma ação que gerasse um resultado constante. Desse modo, na era da informação, a utilização da Internet, email marketing, utilização de aplicativos, plataformas, inbound marketing, blogs, redes sociais, passaram a ser estratégias essenciais das organizações a fim de aproximar de seus clientes, devido ao comportamento do consumidor da era digital. Conforme os mercados e os consumidores mudavam, a aplicação do marketing evoluía e assim surgiram os conceitos de Marketing 1.0, 2.0, 3.0 e 4.0, conforme mostrado no Quadro 1.

Para Almeida Junior et al. (2017), a interação dos consumidores com as marcas, produtos, empresas, outros consumidores e especialistas permitem uma percepção diferenciada que vai além do que a empresa comunica. $O$ mesmo pode ser visto na definição de Vaz (2011), quando afirma que o consumidor se sente mais seguro ao ver a reação ou comentários de outros consumidores semelhantes a ele, não havendo uma confiança total nas informações prestadas pelas organizações. Neste ínterim, os clientes 
passaram a ser mais críticos, tendo um papel muito importante para o marketing, influenciando a decisão de outros consumidores.

Quadro 1. Comparação entre Marketing 1.0, 2.0, 3.0 e 4.0

\begin{tabular}{|l|c|c|c|c|}
\hline Fatores & Marketing 1.0 & Marketing 2.0 & Marketing 3.0 & Marketing 4.0 \\
\hline Objetivo & Vender produtos & $\begin{array}{c}\text { Satisfazer e reter } \\
\text { consumidores }\end{array}$ & $\begin{array}{c}\text { Fazer do mundo um } \\
\text { lugar melhor }\end{array}$ & $\begin{array}{c}\text { Interagir e compartilhar } \\
\text { conteúdo }\end{array}$ \\
\hline $\begin{array}{l}\text { Forças } \\
\text { Propulsoras }\end{array}$ & Revolução Industrial & $\begin{array}{c}\text { Tecnologia da } \\
\text { Informação }\end{array}$ & $\begin{array}{c}\text { Nova onda de } \\
\text { Tecnologia }\end{array}$ & $\begin{array}{c}\text { Revolução causada pela } \\
\text { Internet }\end{array}$ \\
\hline $\begin{array}{l}\text { Como as } \\
\text { empresas veem o } \\
\text { mercado }\end{array}$ & $\begin{array}{c}\text { Compradores de massa, } \\
\text { com necessidades } \\
\text { físicas }\end{array}$ & $\begin{array}{c}\text { Consumidor inteligente, } \\
\text { dotado de coração e } \\
\text { mente }\end{array}$ & $\begin{array}{c}\text { Ser humano pleno, com } \\
\text { coração, mente e } \\
\text { espírito }\end{array}$ & $\begin{array}{c}\text { Além de aspectos } \\
\text { emocionais, o mercado } \\
\text { colaborativo (Rede) }\end{array}$ \\
\hline $\begin{array}{l}\text { Conceito de } \\
\text { Marketing }\end{array}$ & $\begin{array}{c}\text { Desenvolvimento de } \\
\text { produto }\end{array}$ & Diferenciação & $\begin{array}{c}\text { Valores } \\
\text { fidelidade }\end{array}$ \\
\hline $\begin{array}{l}\text { Diretrizes de } \\
\text { marketing da } \\
\text { empresa }\end{array}$ & $\begin{array}{c}\text { Especificação do } \\
\text { produto }\end{array}$ & $\begin{array}{c}\text { Posicionamento do } \\
\text { produto e da empresa }\end{array}$ & $\begin{array}{c}\text { Missão, visão e valores } \\
\text { da empresa }\end{array}$ & $\begin{array}{c}\text { Planejamento, } \\
\text { integração do } \\
\text { tradicional e digital }\end{array}$ \\
\hline $\begin{array}{l}\text { Proposição de } \\
\text { valor }\end{array}$ & Funcional & Funcional e emocional & $\begin{array}{c}\text { Funcional, emocional e } \\
\text { espiritual }\end{array}$ & $\begin{array}{c}\text { Transparência e melhor } \\
\text { Relacionamento }\end{array}$ \\
\hline $\begin{array}{l}\text { Interação com } \\
\text { consumidores }\end{array}$ & $\begin{array}{c}\text { Transação do tipo um- } \\
\text { para-um }\end{array}$ & $\begin{array}{c}\text { Relacionamento um- } \\
\text { para-um }\end{array}$ & $\begin{array}{c}\text { Colaboração um-para- } \\
\text { muitos }\end{array}$ & $\begin{array}{c}\text { Digital, comunidades, } \\
\text { advogados da marca }\end{array}$ \\
\hline
\end{tabular}

Fonte. Adaptado de Kotler, Kartajaya e Setiawan (2012; 2017)

De forma semelhante, Kotler, Kartajaya, Setiawan (2017) afirmam que no passado, os consumidores eram influenciados por ações de marketing e especialistas, entretanto, pesquisas atuais, relatam que o círculo social, compostos por amigos, familia, redes sociais, são fortes influências para os consumidores, o que pode ser verificado em diversas plataformas de avaliação pública, como o TripAdvisor e Yelp.

Após a revolução causada pela Internet, a sociedade se transformou, no que diz respeito a forma de vender, se comunicar e se relacionar, surgindo o marketing digital. Percebe-se que cada vez mais as pessoas estão conectadas, segundo dados do IBGE (2018), no Brasil, pouco mais de 146 milhões de pessoas estão conectadas à Internet, em uma perspectiva de mundo, na publicação do relatório em 2018 pela Hootsuite do We Are Social, aponta que 4 bilhões de pessoas têm acesso à Internet; destes, 3,1 bilhões são usuários ativos de redes sociais.

Para Torres (2009, p. 45), “o marketing digital [...] consiste em utilizar efetivamente a Internet como uma ferramenta de marketing, envolvendo comunicação, publicidade, propaganda e todo arsenal de estratégias e conceitos já conhecidos na teoria do marketing." Oliveira e Saraiva (2019, p. 593) afirmam que "marketing digital é um meio de promover produtos ou marcas nas mídias on-line, de forma específica para cada consumidor, gerando relacionamento e promovendo fidelização".

Em uma visão de unificação do marketing tradicional e o digital, Kotler, Kartajaya, Setiawan (2017, p. 80) afirmam que "o marketing digital não pretende substituir o marketing tradicional. Pelo contrário, ambos devem coexistir, com papéis permutáveis, ao longo do caminho do consumidor". Estes autores estabeleceram que, devido o marketing digital ter características mais controláveis, possui seu foco nos resultados, diferente do marketing tradicional que tem como objetivo iniciar a interação com os consumidores.

No estudo de Oliveira e Saraiva (2019), os autores buscaram entender os impactos causados pelo marketing digital no perfil de consumo da geração Y. Almeida Junior et al. (2017) evidenciaram a importância da utilização das redes sociais como 
estratégia mercadológica. A pesquisa de Silva et al. (2018) enfatizou que é fundamental o gerenciamento das mídias digitais dentro de uma organização.

Desta forma, o marketing tradicional atua na captação de clientes, despertando o interesse para o ato da compra e o marketing digital trabalha na consolidação da marca e da fidelização deste cliente.

\subsection{Dos 4Ps aos 8Ps do marketing}

Os 4Ps ou mix de marketing funciona da seguinte forma, conforme Machado et al. (2012): a empresa desenvolve um produto ou serviço (produto), comunica para o consumidor (promoção), distribui aos locais de comercialização (praça) e determina o preço pelo produto vendido ou serviço oferecidos (preço).

No entanto, Kotler e Keller (2012) afirmam que com o passar do tempo e a complexidade do marketing, estes 4Ps propostos por McCarthy, não representam o cenário por completo, apresentando uma atualização deste mix que é mais representativo para o marketing moderno, são eles: pessoas, processos, programas e performance.

Nesta visão, a variável "Pessoas" está ligada tanto ao fato de que os funcionários são fundamentais para o marketing, mas também diz respeito que as empresas devem enxergar seus clientes como pessoas, compreendê-los em toda sua amplitude e não apenas como aqueles que consomem seus produtos. A variável "Processos" está relacionada a todo fluxo de trabalho e as metodologias que as empresas utilizam. Segundo Kotler e Keller (2012, p. 24), "somente com a instauração do conjunto certo de processos a orientar atividades e programas, uma empresa pode se envolver em relacionamentos de longo prazo mutuamente benéficos".

Quanto aos "Programas", são todas as ações realizadas pela empresa que são direcionadas aos consumidores, sejam elas on-line ou off-line. A "Performance" está ligada ao desempenho do marketing, retratado por meio de indicadores de resultados financeiros e não financeiros, tais como lucratividade, brand equity e customer equity (KOTLER; KELLER, 2012).

Com o surgimento da Internet, ocorre uma formulação específica de um modelo para o marketing digital, a metodologia 8Ps, transformando as estratégias utilizadas pelo marketing tradicional, com abrangência no mundo virtual. Esta metodologia tem o objetivo principal de conhecer o perfil do consumidor, para planejar ações de marketing, formulando estratégias mais eficientes e, assim, atingir um maior número de clientes (VAZ, 2011).

Os 8Ps são formados por: Pesquisa - recolhimento das informações sobre o público alvo e seus preferências; Planejamento - orientação do que será feito em relação aos Ps; Produção - elaboração do que foi planejado; Publicação - disponibilizar informações aos consumidores com condições de compartilhamento; Promoção atividades que promovam as comunicações; Propagação - viralização das informações; Personalização - segmentação e construção de relacionamento com os consumidores; e Precisão - mensuração dos resultados por meio de indicadores (VAZ, 2011).

Apoiados nesta teoria, Braga e Coelho (2018) utilizaram a metodologia do 8Ps para avaliar estratégias de marketing digital usadas por blogueiras de moda, evidenciando a importância da utilização das redes sociais como forma de interação e comunicação com consumidores. De modo semelhante, Steinhorst, Carmo e Mioranza (2015), no estudo sobre a aplicação da metodologia dos 8Ps do Marketing Digital em uma indústria metalúrgica, destacaram a relevância de publicar conteúdos na Internet e 
dar atenção às tendências de mercado. Desse modo, a utilização da metodologia 8Ps, conforme apresentado por Vaz (2011), pode ser seguida por toda organização que queira implantar, acompanhar e avaliar o marketing digital. Ela permite que todo o processo possa ser analisado, contribuindo para a implementação das estratégias formuladas, captação e fidelização de clientes.

\subsection{Ações estratégicas de marketing digital}

Para atingir um resultado mais amplo e eficiente, necessita-se de estratégias com a utilização de ferramentas e ambientes digitais. Um modelo proposto por Torres (2009) apresenta seis ações estratégicas de marketing digital: marketing de conteúdo, marketing nas mídias sociais, marketing viral, e-mail marketing, publicidade on-line e pesquisa on-line. $\mathrm{O}$ monitoramento é utilizado junto com estas ferramentas para garantia do controle dos resultados.

Segundo Torres (2009), o monitoramento integra os resultados das outras seis ações estratégicas. É a partir deste que as empresas podem conhecer conhecerão a eficácia da sua campanha e o retorno de seu investimento, proporcionando uma retroalimentação de seu processo e fornecendo dados para tomada de decisões. Torres (2009) afirma ainda que na Internet os consumidores estão o tempo todo conectados em vários ambientes, mesmo que as ações sejam executadas isoladamente, uma poderá interferir nas outras, sendo que cada uma produzirá um efeito, no qual o todo, gera o resultado.

A primeira ação estratégica do marketing digital é o marketing de conteúdo, para Torres (2009, p. 87), "o marketing de conteúdo é o uso do conteúdo em volume e qualidade suficientes para permitir que o consumidor encontre, goste e se relacione com uma marca, empresa ou produto". O objetivo desta estratégia é manter relacionamento e aproximar-se do cliente, mas antes disso é necessário ser visto para que as pessoas achem a página, o blog ou qualquer canal que a organização poderá gerar conteúdo para atingir este objetivo, sendo parte de uma estratégia de comunicação ampla (TORRES, 2009).

Ações relacionadas ao marketing de mídias sociais são de grande importância para qualquer ação de marketing. O principal objetivo de ações em mídias sociais, além da exposição de comunicações de produtos e valores da organização, é a possibilidade da participação do cliente nas discussões sobre o conteúdo disponibilizado. Para Torres (2009, p. 63) "as mídias sociais são sites na Internet construídos para permitir a criação colaborativa de conteúdo, interação social e o compartilhamento de informações em diversos formatos".

As mídias sociais criam uma rede de relacionamentos, fazendo com que a propagação de informações seja no chamado efeito viral, visto que a informação se amplifica de maneira muito rápida. Neste processo, os indivíduos podem influenciar não apenas um seleto grupo de pessoas, mas comunidades inteiras, e estas comunidades podem influenciar outros grupos e assim por diante (TORRES, 2009). Estar monitorando as mídias sociais, saber o que seu cliente está falando da sua marca ou produto é essencial, pois dependendo da experiência que um cliente teve com seu produto, quando ele transmite sua opinião sem nenhuma resposta por parte da empresa, pode causar grandes prejuízos ou resultados positivos.

O próximo item, o marketing viral, consiste na propagação de conteúdo de maneira rápida e como a Internet proporciona a vivência em rede, o resultado é potencializado. A ideia neste tipo de marketing é que a mensagem se espalhe 
espontaneamente de consumidor em consumidor (TORRES, 2009). As redes sociais, como o Youtube e Facebook, são fortes aliadas nas campanhas de marketing viral, porém, para ter efeito o conteúdo criado deve ser de interesse do maior número de pessoas possível.

Sobre a possibilidade de ações de marketing via e-mails, o denominado e-mail marketing, se concretiza pela obtenção dos endereços eletrônicos - e-mail - dos consumidores para envio de campanhas de marketing. Esta ferramente permite que se crie e mantenha relacionamento com potenciais clientes de maneira direta. O custo é muito baixo comparado com o envio das cartas, por exemplo, porém com o aumento da divulgação neste meio, surgiu também o aumento de mensagens spam e distribuição de vírus eletrônicos (TORRES, 2009).

Outra opção é a pesquisa on-line: parte de uma análise situacional na Internet, uma vez que conhecer o seu consumidor e seus concorrentes é essencial para efetividade das estratégias de marketing. Segundo Torres (2009), esta pesquisa deve abranger algumas áreas para atingir o consumidor, são elas: ferramentas de busca, sites de e-commerce, blogs, mídias, redes sociais e sites de concorrentes. Nesse campo, utiliza-se de três áreas de pesquisa: a de mídias que tem o objetivo de conhecer as fontes de informação sobre seu mercado e consumidor; a pesquisa de opinião que se relaciona diretamente com o consumidor, buscando conhecer a posição deste sobre determinado assunto; e a pesquisa de concorrentes para conhecer seu posicionamento na Internet.

Sobre a publicidade on-line, assim como na tradicional, é realizada para difusão pública de informações associadas as empresas, como um ato de propaganda. A Internet apresenta grandes possibilidades e oportunidades para uma veiculação publicitária. A partir da pesquisa on-line, as empresas devem saber em qual espaço de veiculação deverão investir (TORRES, 2009).

\subsection{Comportamento de consumo e os novos consumidores}

Considerando que o objetivo do marketing é satisfazer as necessidades e desejos dos consumidores por meio da disposição de produtos e serviços, para cumprir seu propósito é recomendada a realização de estudo do comportamento do consumidor. Este estudo contribui opara compreensão do comportamento das pessoas, seus desejos, motivações e necessidades, buscando entender quando e por que compram, porém, não é uma tarefa fácil, devido à complexidade do ser humano e variação de comportamento de pessoa para pessoa (SAMARA; MORSCH, 2005).

O comportamento do consumidor é influenciado por fatores internos (pessoais) e externos (promovidas pelo ambiente) e pelos fatores culturais, sociais, psicológicos e pessoais (SAMARA; MORSCH, 2005; KOTLER; KELLER, 2012).

Seguindo a visão de Kotler e Keller (2012) e Samara e Morsch (2005), os fatores culturais são os principais influenciadores de desejos e comportamento de uma pessoa, estes envolvem a cultura, subcultura e a classe social do consumidor. Desde o nascimento, as pessoas estão expostas ao ambiente que estão inseridas, como por exemplo instituições e famílias.

Para Samara e Morsch (2005, p. 55), "a cultura pode ser definida como a acumulação de valores, crenças, costumes, conhecimento, conceitos, preferências e gostos passados de uma geração para a outra dentro de uma sociedade". A subcultura são grupos específicos dentro de uma cultura, que revelam a identificação e socialização de seus membros. Estas características incluem a idade, nacionalidade, grupos religiosos, grupos raciais. 
O terceiro item são as classes sociais. Trata-se de uma apresentação de estratificação social que compartilham preferências similares como: escolaridade, ocupação, área em que reside, tipo de residência, fonte de riqueza, etc.

Os fatores sociais acabam influenciando na decisão de compra pela opinião de grupos de referência, família, papéis sociais e status, promovendo pressão por aceitação social. Samara e Morsch (2005) afirmam que quando a influência neste quesito é muito forte, as organizações devem atingir primeiramente aos líderes de opinião que influenciam determinado grupo.

O segundo item é a família que consiste no grupo de referência mais influente, sendo formadas por pais, avós, tios, primos, irmãos, cônjuge e filhos. Refere-se ao primeiro nível de interação, determinando o comportamento de consumo deste grupo (SAMARA; MORSCH, 2005). O terceiro item são os papéis e status. As pessoas estão inseridas em diversos grupos, seu comportamento está ligado intimamente ao status, fazendo com que a escolha de produtos seja feita baseando na posição que ocupa nestes grupos (SAMARA; MORSCH, 2005).

Os fatores pessoais são aqueles que exercem influência sobre o indivíduo como: idade e estágio no ciclo de vida, determinando que os padrões de consumo são moldados de acordo com a idade e ciclo da vida que se encontra. A ocupação influencia no sentido de que cada profissão exerce um hábito de consumo diferente, as empresas podem identificar isso e criar produtos para grupos de ocupações específicos, sendo que as circunstâncias também afetam diretamente estes hábitos. Considerando a renda disponível, economias, bens e débitos, estes fatores são interligados a conceitos microeconômicos e macroeconômicos. A personalidade e autoimagem, sendo estes ligados ao conjunto de traços psicológicos distintos. E por último, estilo de vida e valores que revelam o padrão de vida de cada pessoa, expresso por atividades, interesses e opiniões, influenciados também pelos valores (SAMARA; MORSCH, 2005).

Os fatores psicológicos são aqueles que fornecem estímulos para a decisão de compra, sendo que são divididos em quatro fatores, sendo eles: motivação, percepção, aprendizagem e memória. Após a identificação da necessidade, a motivação é aquela que causa determinada ação que, segundo Kotler e Keller (2012), baseia-se em três teorias da motivação humana; A teoria de Freud que concluiu que as forças psicológicas que determinam o comportamento são inconscientes; a de Maslow com a teoria das necessidades, concluindo que as necessidades humanas estão em uma hierarquia que a cada vez que uma necessidade é atendida, outra necessidade hierarquicamente superior se apresenta, sendo elas necessidades fisiológicas, segurança, sociais, estima e autorrealização; e Herzberg com a teoria de dois fatores, aqueles que causam insatisfação e aqueles que causam satisfação.

A percepção é o modo como o consumidor, seleciona, organiza e interpreta as interações recebidas pelo meio para criar uma imagem sobre algo, dependendo da relação dos estímulos físicos com as condições individuais. A aprendizagem está ligada às experiências vivenciadas de cada consumidor, estas podem influenciar em seu comportamento de consumo. A memória, como parte da vivência e experiência, é onde fica armazenada cada uma das experiências com o produto (KOTLER; KELLER, 2012).

Além destes, Samara e Morsch (2005) acrescentam fatores situacionais, são eles: ambiente físico, ambiente social, tempo, razão de compra, estado de espírito e predisposição. O ambiente físico se refere à localização, layout da loja, aromas, sons, luzes e outros. Estes provocam estímulos sensoriais e efeitos emocionais que 
influenciam na tomada de decisão. O ambiente social são aqueles grupos interpessoais que os consumidores estão ligados e que interagem em um processo de compra, como por exemplo, amigos, parentes, vendedores ou até mesmo outros clientes, sendo uma influência informacional, com o aconselhamento. O outro fator é o tempo, que influencia em função de sua disponibilidade. A razão de compra está ligada ao propósito do consumo e a finalidade da compra. Dependendo da razão, a escolha pode variar. E por fim, o fator estado de espírito e predisposição, compreendendo os sentimentos e emoções como ansiedade, raiva, alegria, falta de dinheiro, acabam por influenciar o comportamento humano, inclusive as respostas aos estímulos mercadológicos que consequentemente podem influenciar na tomada de decisão.

Até a efetivação da compra, o consumidor passa por estágios em seu processo de decisão. Samara e Morsch (2005), Kotler e Keller (2012) e Mattar (2011) demonstraram que este processo, embora tendo algumas variações, se assemelham e sugerem que o processo decisório de compra seja composto por cinco etapas: (i) reconhecimento do problema, (ii) busca de informações, (iii) avaliação de alternativas, (iv) decisão de compra e (v) comportamento pós-compra. Todo este conjunto de fatores internos, externos e situacionais influencia diretamente no processo de decisão de compra.

A primeira etapa é reconhecer o problema. Trara-se da detecção da necessidade ou desejo desencadeado por estímulos internos e externos e fatores de influência psicológicos. A segunda etapa é a busca de informações. Nesta etapa o consumidor pesquisa sobre o produto ou serviço reunindo informações, podendo ser de natureza interna, baseado em experiências que o consumidor vivenciou, ou externo, baseado nas experiências de outros, como familia, grupos, mídias sociais, sites. Quanto menor a importância ou mais habitual for o uso do produto ou serviço, menos informação do produto é procurada. A terceira etapa consiste na avaliação de alternativas. Com posse das informações, o consumidor irá avaliar os benefícios de cada produto, de acordo com a sua necessidade e o valor que este entregará para satisfação de sua necessidade. $\mathrm{Na}$ quarta etapa, a decisão de compra, é quando o consumidor irá selecionar o seu produto ou serviço (marca, local, quantidade, ocasião e pagamento) e efetivar a compra. Ele pode ser influenciado por outros, na avaliação de outros consumidores e também por fatores situacionais imprevistos. O comportamento pós-compra, quinta etapa, trata-se daquele que o consumidor usufrui do produto ou serviço e avalia sua satisfação com base em suas expectativas. Caso passasse por uma experiência ruim, o consumidor pode utilizar também de ferramentas disponibilizadas na Internet, como utilizar de plataformas públicas para reclamar do produto ou serviço, que se não for monitorado pela empresa, pode gerar perdas. Com a evolução do mercado, surge o conceito do novo consumidor, conforme comparativo do Quadro 2.

Samara e Morsch (2005) definem como o que consome produtos e serviços em um mercado global, utilizando a Internet cotidianamente para estar mais informado. Transcendem barreiras de fatores culturais, étnicos, sociais, de idade e renda. Neste aspecto, a Sociedade Brasileira de Varejo e Consumo (2018a, 2018b) buscou entender os hábitos de compra e consumo de jovens brasileiros e concluíram que os jovens utilizam muito as mídias sociais, destacando algumas características deste público como interativos, transparentes, pressionados, antenados e ansiosos. No estudo de Madalosso, Gonçalves e Piccin (2016) sobre a gestão das redes sociais em vinícolas, concluíram que as empresas utilizam estratégias de atuação on-line nas mídias sociais para se relacionar com estes novos consumidores, destacando a importância desta interação. 
Quadro 2. Os novos consumidores são diferentes

\begin{tabular}{|l|l|}
\hline Velhos Consumidores & Novos Consumidores \\
\hline Mais passivos e pouco empoderados & Ativistas e mais empoderados \\
\hline Mais fiéis & Menos fiéis \\
\hline Com tempo & Sem tempo \\
\hline Predominantemente locais & Locais e globais \\
\hline Procura satisfazer necessidades & Buscam experiências e satisfazer desejos \\
\hline Menos bem informados & Bem informados \\
\hline Buscam conveniência & Buscam autenticidade \\
\hline Sincronizados & Individuais \\
\hline Conformistas & Independentes \\
\hline Eventualmente envolvidos & Constantemente envolvidos \\
\hline
\end{tabular}

Fonte. Samara e Morsch (2005, p. 248)

Deste modo, diante deste novo consumidor, entender suas características e o seu comportamento, são fatores importantes para o desempenho do negócio, sendo que este tipo de consumidor exige novas atitudes e mudanças na execução do marketing e no posicionamento das empresas, fazendo com que os negócios sejam reinventados, buscando novas ferramentas e soluções.

\section{Procedimentos Metodológicos}

Nesta seção estão elencados os procedimentos metodológicos que configuram o protocolo de pesquisa, bem como sujeitos de pesquisa, a estrutura de coleta de dados e a estrutura de análise. Para definição dos procedimentos metodológicos foi utilizada a classificação de pesquisa utilizada por Prodanov e Freitas (2013) que são: quanto à natureza, objetivos, abordagem do problema e aos procedimentos técnicos.

Quanto à natureza, a pesquisa se caracteriza como aplicada que, segundo Moresi (2003), é aquela que gera conhecimentos para aplicação prática e que seja utilizada para solução de problemas. Quanto aos objetivos, a pesquisa foi do tipo descritiva que, segundo Gil (2019) e Prodanov e Freitas (2013), tem por objetivo descrever as características de determinada população ou o estabelecimento de relações entre variáveis. Logo, este estudo buscou descrever as estratégias de marketing digital utilizadas pelas empresas do varejo de vestuário de Cuiabá-MT e descrever o perfil e comportamento dos consumidores desta cidade.

O método utilizado para abordagem do problema foi o misto que envolve pesquisa quantitativa e qualitativa. Segundo Prodanov e Freitas (2013), a pesquisa quantitativa tem o objetivo de traduzir dados estatísticos, números em opiniões $\mathrm{e}$ informações para classificá-las e analisá-las. A pesquisa qualitativa considera a existência de um vínculo indissociável entre o mundo objetivo e a subjetividade do sujeito que não pode ser traduzido em números. Diante disso, utilizou-se a quantitativa para manusear os resultados dos questionários aplicados e a qualitativa para manusear os resultados das entrevistas realizadas com os gestores das empresas e profissional de marketing.

Quanto aos procedimentos técnicos, na etapa quantitativa tem-se o uso do levantamento, que, segundo Prodanov e Freitas (2013), envolve a interrogação direta de pessoas buscando conhecer o comportamento por meio de um questionário. As principais vantagens deste método estão no conhecimento direto da realidade, economia, rapidez e quantificação (GIL, 2019). Esta técnica foi utilizada neste estudo com a aplicação de questionários. 
$\mathrm{Na}$ etapa qualitativa, optou-se pelo uso da pesquisa de campo que, conforme Prodanov e Freitas (2013), tem por objetivo conseguir informações acerca de um problema inicial que queiramos descobrir, como novos fenômenos ou as relações entre eles. Deste modo, esta técnica foi utilizada realizando entrevistas com gestores e profissionais de marketing do varejo de vestuário da cidade de Cuiabá.

Sujeitos da pesquisa são aquelas pessoas que irão fornecer os dados para a pesquisa (VERGARA, 2016). Seguindo esta linha, os sujeitos da pesquisa foram os consumidores de varejo de vestuário de Cuiabá, gestores/proprietários de empresas varejistas de vestuário e profissional de marketing digital. Para definição da amostragem dos consumidores foi utilizada por conveniência (LAKATOS; MARCONI, 2003; PRODANOV; FREITAS, 2013). Utilizou-se uma amostra de 160 pessoas para coleta dos dados quantitativos referente ao comportamento do consumidor de varejo de vestuário. Ademais, foram entrevistados dois gestores de empresas do ramo de varejo de vestuário e um profissional de marketing digital.

Para coleta de dados quantitativos foi utilizado como instrumento um questionário estruturado disponibilizado on-line via Google Forms®, composto por questões fechadas de múltipla escolha e por questões padronizadas seguindo uma escala tipo Likert de cinco níveis, sendo 1 representando a percepção "discordo plenamente ou sem importância alguma" e 5 representando a percepção "concordo plenamente ou muito importante". A estrutura do questionário foi estabelecida baseada em Poio, Trigueiro e Leite (2018) e as questões construídas a partir do referencial teórico utilizado no presente estudo.

Segundo Lakatos e Marconi (2003), questionário é um instrumento de coleta de dados, composto por perguntas ordenadas a serem respondidas por quem está se estudando. Este instrumento foi composto por treze perguntas agrupadas em três blocos. O primeiro bloco tratava da identificação do perfil dos respondentes e hábitos de consumo, contendo nove questões, o segundo bloco abordava sobre comportamento de compra de vestuário, abrangendo duas questões, e o terceiro bloco sobre influências de compra, englobando uma questão.

O questionário foi submetido a um pré-teste respondido por cinco pessoas, a fim de validar o instrumento de coleta de dados e, após as modificações necessárias, pode-se dar início na aplicação. O questionário foi disponibilizado no período de 26 de junho de 2019 a 8 de julho de 2019.

$\mathrm{Na}$ etapa qualitativa foram realizadas entrevistas com gestores/proprietários de empresas do ramo de varejo de vestuário e um profissional de marketing digital. Foi estabelecido um roteiro semiestruturado compostos por perguntas abertas que tinham por objetivo identificar as estratégias de marketing digital utilizadas pelas empresas para se relacionar com os consumidores. As entrevistas foram realizadas presencialmente no período de 26 de junho de 2019 a 8 de julho de 2019. A entrevista é a obtenção de informação de um entrevistado sobre determinado assunto, sendo que estas podem ser estruturadas, não estruturadas ou painel (PRODANOV; FREITAS, 2013).

Para análise dos dados coletados, primeiramente foi realizada a transcrição das entrevistas para viabilização da análise de conteúdo. Esta análise foi composta de três etapas: Pré-análise, trata-se da exploração do material, tratamento e interpretação dos dados. Na pré-análise o material é selecionado e é definido os procedimentos, após ocorre a exploração do material, que é a implementação de tais procedimentos, e por final, ocorre o tratamento dos dados e interpretação, possibilitando inferenciar sobre os resultados da investigação (BARDIN, 2011). 
Posteriormente, foi realizada a análise dos dados quantitativos, coletados por meio da aplicação dos questionários. Nesta etapa, a análise se deu por intermédio da tabulação dos dados eletronicamente, com apoio do software Microsoft Excel®. Na sequência, foi utilizada estatística descritiva para fornecer indicadores como média, moda, mediana e desvio-padrão.

\section{Apresentação e Discussão dos Resultados}

Nessa seção serão apresentados e discutidos os dados obtidos na pesquisa. Inicialmente abrage as caracterísitcas das organizações participantes e análise das entrevistas realizadas com a Loja A e Loja B com intuito de investigar e relatar as principais estratégias de marketing digital utilizadas pelas empresas para ter um maior relacionamento com seus clientes. $\mathrm{Na}$ sequência, estão apresentados os dados quantitativos explanando acerca do perfil do consumidor de varejo de vestuário, identificando o comportamento de compra e influenciadores de decisão de compra. Por fim, são apresentadas as discussões sobre os pontos de convergência e divergência entre os resultados obtidos tanto na etapa qualitativa quanto na quantitativa a fim de comparar a visão das empresas, do especialista em marketing digital e a do consumidor.

\subsection{Histórico das empresas, estratégias de marketing e perspectiva de comportamento do consumidor}

A Loja B é uma empresa recente no mercado e foi inaugurada em 2017. A gestora relata que escolheu este ramo de atuação por ver uma necessidade do público de comprar roupas de qualidade a um preço mais acessível, verificando um modelo de negócio semelhante que atuava em lojas físicas, a partir daí decidiu abrir a loja apenas no e-commerce por meio de site, Instagram e Facebook. O valor que é entregue ao cliente é preço único e acessível atrelado com a qualidade nas roupas. Os produtos oferecidos são exclusivos para o público feminino de 15 a 50 anos.

A Loja A iniciou as suas atividades em 2003. No início era uma loja multimarca que entregava o conceito de sustentabilidade em suas roupas, com diversos tipos de tecidos, principalmente os mais frescos por conta do clima quente de Cuiabá e depois virou uma marca própria. Tem a produção e mão de obra local, entregando o conceito além da sustentabilidade atuando com o conceito de cultura envolvido nas roupas, com estampas de dizeres e gírias cuiabanas, comidas típicas, e outros símbolos culturais. Atua em Cuiabá e Chapada dos Guimarães em lojas físicas, sendo uma delas em um shopping. No entanto, a gestora alega que a empresa tem um projeto de vendas também no marketplace do Facebook. Os produtos oferecidos são para todos os gêneros, tendo o seu público-alvo com idade entre 35 a 40 anos.

No sentido de entender os canais de relacionamentos e de venda das empresas, ambas possuem como canal de relacionamentos as redes sociais. A loja A utiliza lista de transmissão pelo Whatsapp, Instagram e Facebook, em termos comparativos o acompanhamento das atividades de e-comerce é menor na loja A do que na Loja B.

A Loja B trabalha exclusivamente no e-commerce, possui suas atividades nas redes sociais e em sites, com muita atuação e como parte da rotina da empresa.

Assim como na Loja A, a Loja B utiliza de lista de transmissão pelo Whatsapp, Instagram e Facebook com a integração entre redes sociais e site, como afirma a gestora: "Hoje, a gente tem o site que é o principal canal de vendas, e a gente usa o Instagram e Facebook como forma de marketing, a gente anuncia nas redes sociais e traz o cliente para o site". 
Quando indagados sobre ter lojas físicas ou estarem exclusivo no e-commerce, houve algumas divergências. $\mathrm{Na}$ Loja $\mathrm{B}$, por ser e-commerce, a gestora disse que não possui loja física por conta do custo envolvido e também porque como relatado pela mesma "a maioria das lojas a tendência é ficar no virtual".

Destaca ainda a importância de anunciar e publicar para promover a comunicação com os clientes e criar relacionamento. Retratou que existe diferença do preço do produto em lojas físicas e em lojas virtuais, como a loja dela preza pelo preço acessível das roupas, se houvesse migração para lojas físicas, ou abrisse pontos de vendas, as roupas seriam mais caras.

Para a gestora da Loja A, por atuar com lojas físicas, entende a importância do relacionamento por meio de redes sociais, mas preza por toda a ambientação da loja para receber seus clientes. Segundo a gestora "as pessoas gostam de vir, de conversar, da energia da loja, então se eu estivesse só no virtual, isso faria falta".

Dias e Hemais (2015) destacaram que o público de baixa renda possui preferência em consumir em lojas físicas tendo receio em efetuar compras em lojas virtuais. Os entrevistados alegaram que os sites não são seguros e podem oferecer ameaças de perda de dados. Outro ponto destacado é o fato de que em lojas físicas, os consumidores possuem a experiência do contato com o produto, da interação com o ambiente da loja e com os vendedores. O que pode ser observado é que no ramo de vestuário os clientes usufruem da experiência de provar as roupas, podendo gerar maior segurança em comprar, fato este que não acontece no ambiente virtual.

A fim de facilitar o entendimento acerca do histórico das empresas estudas, o público alvo, valor, canais de relacionamento e canais de vendas destas empresas, foi elaborado o Quadro 3.

Quadro 3. Características das Empresas Estudadas

\begin{tabular}{|l|l|l|}
\hline \multicolumn{1}{|c|}{ Variável } & \multicolumn{1}{c|}{ Loja A } & \multicolumn{1}{c|}{ Loja B } \\
\hline Tempo de Mercado & 16 Anos & 2 Anos \\
\hline Valor Entregue & Sustentabilidade e Cultura & $\begin{array}{l}\text { Preço Unico e acessível/ } \\
\text { qualidade }\end{array}$ \\
\hline Público-Alvo & $\begin{array}{l}\text { Todos gêneros com idade entre 35 } \\
\text { a 40 anos. }\end{array}$ & Feminino de 15 a 50 anos \\
\hline $\begin{array}{l}\text { Canais de } \\
\text { Relacionamento }\end{array}$ & $\begin{array}{l}\text { Lista de transmissão e redes } \\
\text { sociais, lojas físicas. }\end{array}$ & $\begin{array}{l}\text { Lista de transmissão, redes } \\
\text { sociais e site, com forte } \\
\text { monitoramento. }\end{array}$ \\
\hline Canais de Vendas & Lojas Físicas & E-commerce \\
\hline
\end{tabular}

Fonte. Dados da pesquisa (2019)

Com relação à importância do marketing digital, ambas as empresas entendem da sua importância, este fator pode trazer um aumento no relacionamento com seus clientes, e posteriormente aumentar o fluxo de vendas. A Loja B relata que $98 \%$ do marketing de sua empresa é por meio do Instagram, canal pela qual se realiza toda a massa de propaganda, impulsionando suas publicações para que chegue a potenciais clientes.

A gestora da Loja A concorda que o marketing digital é fundamental para impulsionar suas vendas e percebe que falha por não ter tantas publicações. Observa-se que ambas as empresas reconhecem a importância e a necessidade de estar no ambiente virtual para que haja um relacionamento mais próximo com seus clientes, promovendo 
ações para consolidação da marca e da fidelização do cliente (KOTLER, KARTAJAYA, SETIAWAN, 2017).

Porém, estas necessitam de ações mais planejadas, seguindo a metodologia dos 8Ps de Vaz (2011) por exemplo. Nesta mesma linha, nas entrevistas foram indagadas sobre que ações de marketing digital são feitas pelas empresas, conforme Quadro 4.

Quadro 4. Comparativo entre as ações de marketing digital realizadas pelas empresas

\begin{tabular}{|l|l|l|}
\hline $\begin{array}{l}\text { Ações de marketing } \\
\text { digital }\end{array}$ & \multicolumn{1}{|c|}{ Loja A } & \multicolumn{1}{c|}{ Loja B } \\
\hline Marketing de conteúdo & Não realizam & Não realizam \\
\hline $\begin{array}{l}\text { Marketing de mídias } \\
\text { sociais }\end{array}$ & $\begin{array}{l}\text { Possuem pouca presença } \\
\text { nas redes sociais }\end{array}$ & $\begin{array}{l}\text { Possuem muita presença no } \\
\text { Instagram e Facebook. }\end{array}$ \\
\hline Pesquisa On-line & $\begin{array}{l}\text { Desconhecem seu público } \\
\text { na Internet. }\end{array}$ & $\begin{array}{l}\text { Realizam pesquisas, inclusive } \\
\text { novas ações são feitas a partir de } \\
\text { monitoramento. }\end{array}$ \\
\hline E-mail marketing & $\begin{array}{l}\text { Não usam o } \text {-mail, mas } \\
\text { utilizam do Whatsapp }\end{array}$ & $\begin{array}{l}\text { Usam a } \text { newsletter do site para } \\
\text { informação aos clientes. E também } \\
\text { lista de transmissão de Whatsapp. }\end{array}$ \\
\hline Publicidade On-line & $\begin{array}{l}\text { Poucas publicações e não } \\
\text { realizam propagandas } \\
\text { pagas }\end{array}$ & $\begin{array}{l}\text { Realizam propagandas pagas nas } \\
\text { mídias sociais, alta publicação e } \\
\text { divulgação de peças. }\end{array}$ \\
\hline Influenciadores digitais & $\begin{array}{l}\text { Fazem parcerias com } \\
\text { influenciadores digitais. }\end{array}$ & $\begin{array}{l}\text { Trabalha com parcerias junto a } \\
\text { blogueiros e influenciadores } \\
\text { digitais. }\end{array}$ \\
\hline Monitoramento de ações & Não realizam & $\begin{array}{l}\text { Realizam grande monitoramento de } \\
\text { ações por meio do Google } \\
\text { Analytics, e outras ferramentas do } \\
\text { Instagram }\end{array}$ \\
\hline $\begin{array}{l}\text { Monitoramento de sites } \\
\text { de opinião pública }\end{array}$ & Não monitoram & $\begin{array}{l}\text { Não monitoram, mas possuem } \\
\text { canal para o cliente deixar sua } \\
\text { sugestão }\end{array}$ \\
\hline $\begin{array}{l}\text { Encontrabilidade da } \\
\text { empresa }\end{array}$ & Uso de hashtags & $\begin{array}{l}\text { Uso de } \text { hashtags e propagandas } \\
\text { patrocinadas. }\end{array}$ \\
\hline
\end{tabular}

Fonte. Dados da pesquisa (2019)

Em linhas gerais, baseando-se nas ações de marketing digital propostas por Torres (2009), verificou-se que a Loja A possui menor presença digital e realiza menos ações de marketing digital quando comparado com a empresa Loja B que possui muita presença digital com utilização de várias ações e constante monitoramento para realização de novas ações mais assertivas e também para analisar o retorno por ação. Fato este que pode ser visto devido à empresa atuar exclusivamente no e-commerce, ou seja, se ela não trabalhar para que seu cliente a encontre e fazer uma constante publicação e apresentação de portfólio em site ou redes sociais, possivelmente não terá resultados positivos. Especificamente precisa primeiramente ser vista para assim realizar vendas.

Nestes dados ocorreram divergências em algumas ações como a parceria com influenciadores digitais para divulgação de seu produto. A Loja A percebeu que em suas ações com influenciadores obteve um aumento de seguidores e visualizações, alegando que traz muito retorno. A Loja B relata que fez parcerias com influenciadores digitais e não obteve o retorno esperado. Esta empresa ainda analisou o custo benefício entre a 
ação por meio de influenciadores e a propaganda paga no Instagram. O retorno por meio da publicidade no Instagram foi melhor e teve maior alcance.

Posteriormente, foram indagadas sobre o comportamento de compra de seus clientes, ambas as gestoras afirmam que as empresas conhecem o comportamento de compra de seus clientes, divergindo apenas na sua atuação. $\mathrm{Na}$ Loja $\mathrm{B}$, a gestora relata $\mathrm{o}$ comportamento dos clientes a partir de métricas fornecidas pelos sites, quanto ao volume de compra, quantidade de cancelamentos e outras situações, mas não abordou sobre o comportamento de seus clientes em redes sociais. A gestora da Loja A retrata que parte de seu público são fãs da marca e percebe o envolvimento da cultura na compra de seu produto.

Nota-se que as empresas seguem o que Samara e Morsch (2005) caracterizam como o estudo do comportamento de consumo. Destaca-se ainda que no e-commerce, como o da Loja B, saber o que o cliente está pesquisando, o que comprou, como comprou, pode ser feito de maneira automática com uso de ferramentas como o Google Analytics.

A partir disto, foram indagados a respeito dos fatores que influenciam de compra. A gestora da Loja A destaca a contribuição da cultura, uma vez que seus produtos retratam a cultura cuiabana, utilizam também de conceitos de produto ecológico. Outro ponto apresentado é a influência causada por amigos e família, como trabalha com marca própria, quando seus clientes estão com seus produtos, despertam curiosidades e trazem clientes para loja. Estes resultados estão alinhados ao que Samara e Morsch (2005), Kotler e Keller (2012) definem como fatores que influenciam o comportamento de consumo, como fatores culturais, sociais, pessoais e psicológicos.

A Loja B, quanto aos fatores de influência, um dos aspectos que trabalha é em relação ao aumento de peças de acordo com as festividades do ano, como natal, dia das mães, atendendo sazonalidades. Outro fator que é destacado é em relação ao produto, preço e a qualidade oferecida.

Finalizado a análise da etapa qualitativa, que teve como objetivo apresentar e discutir as estratégias de marketing digital utilizadas pelas lojas entrevistadas, complementou-se com a etapa quantitativa com consumidores do segmento de varejo de vestuário, apresentada na subseção a seguir.

\subsection{Análise dos dados da pesquisa com os consumidores}

Esta etapa da coleta de dados foi executada mediante o emprego de um formulário on-line cujo acesso foi disponibilizado aos consumidores de Cuiabá por meio de compartilhamento em redes sociais.

A partir dos questionários aplicados com os 160 participantes, chegou-se ao perfil desta amostra de consumidores do varejo de vestuário em Cuiabá. Desse modo, a primeira parte dos resultados diz respeito ao perfil socioeconômico dos respondentes da pesquisa descrito na Tabela 1.

O perfil socioeconômico dos consumidores de varejo de vestuário é na maior parte do gênero feminino $(57,5 \%)$. Em relação à idade, 52,5\% dos respondentes afirmam ter de 19 a 29 anos. Quanto ao estado civil 60,3\% são solteiros. Em relação à escolaridade, $34,4 \%$ possuem nível superior incompleto, $24,4 \%$ tem o superior completo, 4,4\% pós-graduação incompleta e 15,6\% possuem pós-graduação completa, dados estes demonstram que a maioria do seu público tem alta escolaridade, visto que $78,8 \%$ dos respondentes afirmaram possuir nível superior (cursando ou completo) e/ou também ter uma pós-graduação (cursando ou completa). No que diz respeito a renda 
mensal, 68,8\% dos respondentes afirmaram possuir renda de até $\mathrm{R} \$ 3.000,00$, seguindo a classificação de classe social do IBGE, a grande maioria dos participantes da pesquisa são de classe $\mathrm{D}$ e E.

Tabela 1: Perfil socioeconômico dos participantes da pesquisa, etapa quantitativa.

\begin{tabular}{lcc}
\hline \multicolumn{1}{c}{ Variável } & Frequência & \% \\
\hline Gênero & 68 & 42,5 \\
Masculino & 92 & 57,5 \\
Feminino & & \\
Idade & 9 & $5,6 \%$ \\
Até 18 anos & 84 & $52,5 \%$ \\
De 19 a 29 anos & 67 & $41,9 \%$ \\
Acima de 30 anos & & \\
Estado Civil & 98 & $61,3 \%$ \\
Solteiro (a) & 38 & $23,8 \%$ \\
Casado (a) & 24 & $15 \%$ \\
Relação Estável / Divorciado(a) & & \\
Escolaridade & 34 & $58,3 \%$ \\
Fundamental / Médio & 94 & $20 \%$ \\
Superior & 32 & $68,8 \%$ \\
Pós-Graduação & & $13,7 \%$ \\
Renda Mensal & 110 & $17,5 \%$ \\
Até R\$ 3.000 & 22 & \\
De R $\$$ 3.000 à R \$ 5.000 & 28 & \\
Acima de R \$ 5.000 & & \\
\hline
\end{tabular}

Fonte. Dados da pesquisa (2019)

Para entender quais as redes sociais os consumidores possuíam conta, os resultados foram elencados na Tabela 2. Como a questão permitia marcar mais de uma opção, os resultados são mostrados por redes sociais, destacando a frequência e percentual, ou seja, dos 160 respondentes, quantos destes marcaram cada alternativa apresentada.

Tabela 2. Que redes sociais os consumidores possuem conta.

\begin{tabular}{cccc}
\hline Redes Sociais & Frequência & Percentual & $\mathrm{N}^{\mathbf{o}}$ Total de Respondentes \\
\hline Facebook & 144 & $90 \%$ & 160 \\
Instagram & 136 & $85 \%$ & 160 \\
Youtube & 120 & $75 \%$ & 160 \\
Google + & 75 & $46,9 \%$ & 160 \\
Pinterest & 47 & $29,4 \%$ & 160 \\
Twitter & 41 & $25,6 \%$ & 160 \\
Tumblr & 10 & $6,3 \%$ & 160 \\
\hline
\end{tabular}

Fonte. Dados da pesquisa (2019)

Observa-se na Tabela 2 as redes sociais que os respondentes mais possuem conta/acesso são Facebook (90\%), Instagram (85\%) e Youtube (75\%). Ressalta-se ainda a importância das empresas investirem em relacionamento em mídias sociais, principalmente nestas mais acessadas, uma vez que grande quantidade dos respondentes está nas redes sociais.

Em consonância com esta visão, quando os consumidores foram indagados sobre quanto tempo costumam acessar as redes sociais ao longo do dia, 44,4 \% destes 
afirmaram acessar as redes sociais de 1 a 3 horas, e 24,4\% de 3 a 6 horas, isto é, 68,8\% dos consumidores, acessam as redes sociais diariamente em torno de 1 a 6 horas diárias, destacando que estes estão cada vez mais presentes nas redes sociais, se relacionando diariamente. Os resultados corroboram com a pesquisa da Sociedade Brasileira de Varejo e Consumo (2018a, 2018b) que concluíram que os jovens utilizam muito as mídias sociais.

A fim de delimitar o comportamento de compra dos consumidores de vestuário, foi proposto que elencassem onde costumam realizar suas compras, com que frequência costuma comprar roupas e qual a forma de decisão no momento da compra. Conforme os resultados da Tabela 3, mesmo com pesquisas indicando o aumento de vendas no $e$ commerce, para os consumidores de vestuário de Cuiabá, a compra em loja física ainda é predominante $(83,1 \%)$, e em lojas virtuais apenas $16,9 \%$. Com relação a frequência, costumam realizar compras bimestrais e trimestrais $(45 \%)$, sendo que a compra é mais ou menos planejada $(55 \%)$.

Tabela 3. Perfil de compra dos consumidores de varejo de vestuário.

\begin{tabular}{lcc}
\hline \multicolumn{1}{c}{ Variável } & Frequência & \% \\
\hline Local onde compram & & \\
Lojas Físicas & 133 & $83,1 \%$ \\
Lojas Virtuais & 27 & $16,9 \%$ \\
Frequência que compram & 26 & $16,3 \%$ \\
Semanal/Mensal & 40 & $25 \%$ \\
Bimestral & 32 & $20 \%$ \\
Trimestral & 39 & $24,4 \%$ \\
Semestral & 23 & $14,4 \%$ \\
Anual & & \\
Decisão de Compra & 51 & $31,9 \%$ \\
Bem planejada & 88 & $55 \%$ \\
Mais ou menos planejada & 21 & $13,1 \%$ \\
Nenhum planejamento &
\end{tabular}

A seguir, na Tabela 4 são apresentados os resultados referentes ao grau de concordância ou discordância dos consumidores quando indagados sobre a associação do ato de compra de roupas, tendo a intensidade representadas pelas sentenças que inicia em 1 (discordo totalmente) e termina em 5 (concordo totalmente).

Tabela 4. Variáveis de associação ao ato de compra.

\begin{tabular}{lcccc}
\hline \multicolumn{1}{c}{ Variável } & Média & Moda & Mediana & Desvio Padrão \\
\hline Necessidade & 4,18 & 5 & 5 & 1,15 \\
Lazer/Ocasião & 3,53 & 4 & 4 & 1,18 \\
Ato Compulsivo & 2,40 & 1 & 2 & 1,38 \\
Tendência em seguir moda & 2,36 & 1 & 2 & 1,35 \\
Aproveitar promoções & 3,91 & 5 & 4 & 1,20 \\
Desejo & 3,51 & 4 & 4 & 1,36 \\
Ato Impulsivo & 2,51 & 1 & 3 & 1,38 \\
\hline
\end{tabular}

Fonte. Dados da pesquisa (2019)

Segundo os dados relatados na Tabela 4, foi possível identificar que as variáveis de associação com o ato de compra que obtiveram maior média de concordância foram: 
"Necessidade" (4,18), “Aproveitar promoções” (3,91), "Lazer/Ocasião (3,53) e "Desejo" (3,51). Para elucidar tal constatação, a maior moda, ou seja, o resultado que mais se repetiu, foram nas variáveis "Necessidade" e "Aproveitar as promoções" obtendo o valor 5 de concordância total. Nota-se também que os desvios-padrão obtidos pelas variáveis "Necessidade" $(1,15)$, "Lazer/Ocasião" $(1,18)$, “Aproveitar as promoções" $(1,20)$ foram as mais homogêneas, isto é, não tiveram tanta variação nas respostas dos participantes, diferente da variável "Desejo" que apresenta um desviopadrão mais disperso $(1,36)$. Observa-se que são consumidores mais racionais, que seguem o processo de compra mais detalhado, partindo do reconhecimento do problema pela necessidade, conforme Hawking e Mothersbaugh (2019).

As variáveis que receberam menores médias de concordâncias foram "Tendência em seguir moda" $(2,36)$, "Ato Compulsivo" $(2,40)$ e "Ato Impulsivo" $(2,51)$, nas duas primeiras menores mais de $50 \%$ dos respondentes responderam que discordam parcialmente. Quanto aos desvios-padrão obtidos, "Ato Impulsivo" e "Ato Compulsivo" obtiveram o resultado 1,38 e "Tendência em seguir moda" obteve o valor 1,35. Observa-se que estas variáveis representaram os maiores resultados de desvio-padrão, o que caracteriza uma variação significativa na opinião dos respondentes da pesquisa.

No conjunto, os achados da pesquisa a respeito da associação do ato de compra, o consumidor cuiabano realiza suas compras por necessidade, gosta de aproveitar promoções e faz compras a partir de uma ocasião ou festa para assim satisfazer seus desejos de compra. Além dos resultados apresentados, a fim de entender os fatores que influenciam o ato de compra no segmento, foi proposto que avaliassem em grau de importância os seguintes atributos constantes na Tabela 5, sendo que sua percepção varia do valor 1 para "pouco importante" e 5 para "muito importante".

Tabela 5. Variáveis de influência ao efetuar uma compra

\begin{tabular}{lcccc}
\hline \multicolumn{1}{c}{ Variável } & Média & Moda & Mediana & DP* \\
\hline Preço do Produto & 4,43 & 5 & 5 & 0,92 \\
Atendimento no processo de compra & 4,09 & 5 & 4 & 1,17 \\
Comodidade para compra & 3,99 & 4 & 4 & 1,02 \\
Empresa ter loja física & 3,84 & 5 & 4 & 1,23 \\
Características do produto no site da empresa & 3,82 & 5 & 4 & 1,28 \\
Informações sobre o produto em sites de opinião & 3,74 & 5 & 4 & 1,27 \\
pública e avaliação & 3,44 & 4 & 4 & 1,23 \\
Opinião de amigos e família & 3,01 & 4 & 3 & 1,26 \\
Anúncios em redes sociais da empresa & 2,95 & 4 & 3 & 1,32 \\
Relacionamento por redes sociais & 2,87 & 3 & 3 & 1,22 \\
Destaque em sites de busca & 2,47 & 1 & 2 & 1,34 \\
Opinião de Influenciadores digitais & 2,28 & 1 & 2 & 1,18 \\
E-mails publicitários &
\end{tabular}

Fonte. Dados da pesquisa (2019). Nota. *Desvio-Padrão.

Utilizando da média estatística foi possível identificar que as variáveis "Preço do Produto" (4,43), "Atendimento no processo de compra" $(4,09)$, "Comodidade para compra" $(3,99)$, "Empresa ter loja física" $(3,84)$, "Característica do produto no site da empresa" $(3,82)$ e "Informações sobre o produto em sites de opinião pública e avaliação" $(3,74)$ são as principais influenciadoras do ato de compra. A opinião que mais se repetiu (moda) entre estes foram o de importante (4) e o de muito importante (5). Constata-se que os participantes são mais influenciados por fatores externos, desenvolvidos pelas atividades de marketing tradicional, conforme explanado no 
modelo de Hawking e Mothersbaugh (2019). A única variável que apresentou média mais alta nas ações de marketing digital foi as informações sobre o produto em sites de opinião pública e avaliação, que caracterizam ações de monitoramento do marketing digital, segundo Torres (2009).

Quanto às variáveis que receberam menores médias quanto à influência da compra estão: "E-mails publicitários" (2,28), "Opinião de influenciadores digitais $(2,47)$, "Destaque em sites de busca" $(2,87)$, "Relacionamento por redes sociais $(2,95)$, "Anúncios em redes sociais da empresa" $(3,01)$ e "Opinião de amigos e família" $(3,44)$. Quanto ao desvio-padrão, as variáveis "Preço do Produto" $(0,92)$ e "Comodidade para compra" (1,02) apresentaram os desvios-padrão menores, o que representa maior concordância nas respostas. Outra questão a ser salientada são os elevados valores obtidos pelo desvio-padrão nas variáveis "Opinião de Influenciadores Digitais" $(1,34)$ e "Relacionamento por redes sociais" (1,32), representando uma variação nas respostas, devido os dados obtidos estarem mais dispersos.

Analisados os dados quantitativos, constata-se que as variáveis que são pertinentes às ações de marketing digital, nesse grupo pesquisado, não são consideradas importantes para sua decisão de compra.

\subsection{Análise das convergências e divergências da visão das empresas, visão do consumidor e visão de especialista em marketing digital}

Com o propósito de melhor entender em quais pontos a visão do consumidor se encontra e se distancia da percepção dos varejistas de vestuário, desenvolveu-se esta subseção para comparar os resultados obtidos nos dados quantitativos e qualitativos, comparando também com os dados coletados a partir da entrevista com o especialista em marketing digital.

$\mathrm{O}$ primeiro ponto que cabe destacar é quanto a presença das empresas em redes sociais como Facebook e Instagram, uma vez que, na pesquisa com os consumidores, 90\% dos respondentes possuem Facebook e $85 \%$ possuem Instagram, redes estas que as empresas desta pesquisa possuem presença, com mais intensidade na Loja B que realiza diversas ações nestes canais. Outro ponto a ser destacado em relação às redes sociais é o tempo diário que os consumidores estão acessando, 68,8\% dos consumidores alegam estar de 1 a 6 horas diárias em suas redes sociais, destacando a importância da presença das empresas em redes sociais.

Para evidenciar esta questão o especialista em marketing digital alega que a empresa e a propaganda devem estar onde o público está e se na Internet conseguem potencializar isso, trata-se de uma estratégia que possibilita vantagem quando utilizada pelas empresas.

[...] tem uma máxima da publicidade que é a propaganda está onde o povo está, é fácil isso, se tem bastante gente em determinado local, certamente terá empresas querendo atingir essas pessoas, independente do veículo, independente do meio, se tiver um aglomerado de pessoas ali é um potencial local de fazer anúncios e tal, e é o mesmo olhar para Internet. [...] os brasileiros ficam muito tempo conectados, passam muitas horas do dia, tem alguns estudos aí que falam que ficam de 6 a 8 horas por dia conectados, ou seja, quando tá acordado as pessoas estão conectadas, então é um potencial que se você não tá lá, você tá desperdiçando [...] 
O entrevistado relata ainda que este marketing digital é o marketing tradicional com ferramentas, que se forem bem aproveitadas é uma vantagem que pode ajudar a empresa. Dentre as vantagens incluem criar relacionamentos, fazer segmentações mais efetivas, usar métricas de resultados para medir suas ações, entender também todo percurso do cliente na Internet, sendo que as ações feitas na Internet são potencializadas. Não se trata mais de simples boca a boca e sim uma comunicação em escala.

[...] então eu consigo falar de um para muitas pessoas entendeu, em vez de ser só uma mensagem de um para um picadinho, é de um para um para vários, então cada pessoa que a gente tá atingindo vai ter aquela sensação que aquela publicação está sendo feita só para ela, de fato está, mas está tendo uma comunicação para várias outras pessoas também né, diferentes aí, então você consegue fazer de um para um em escala.

Outro fato a ser evidenciado é o local onde os consumidores realizam suas compras, $83,1 \%$ em lojas físicas, retratando a importância dada pela Loja A, visto que este segmento promove uma situação que talvez outros segmentos não tenham, como a sensação de provar roupas e a segurança na compra. Sendo assim, para este público, é interessante as empresas deste segmento possuírem lojas físicas, ou também podendo adotar o conceito de omnichannel, proposto por Souza e Serrentino (2002), tendo presença digital e lojas físicas.

Quanto à associação do ato de compra, ressalta-se um ponto relatado pelos consumidores como destaque o de aproveitar as promoções. Em consonância a este aspecto, a variável preço do produto foi apontada como fator relevante de influência, fato este que pode ser percebido pelo maior número de respondentes que se enquadram no grupo renda de até $\mathrm{R} \$ 3.000,00(68 \%)$.

Por fim, o fator de maior destaque foi quanto a influência da compra junto aos consumidores pesquisados. Variáveis como e-mails publicitários, opinião de influenciadores digitais, destaque em sites de busca, relacionamento por redes sociais e anúncios em redes sociais da empresa tiveram pouca importância no que diz respeito a influência para realização de compras, mesmo que estes alegaram estar grande parte do dia conectado em uma rede social. Em contraste, os gestores das empresas deram grande importância nestas ações.

No entanto, tal fato pode ser explicado na entrevista com o especialista em marketing digital, na qual alega que existem dois grandes grupos de ações de marketing digital, o primeiro aborda a encontrabilidade, nesta, o cliente precisa encontrar a empresa ou o produto que a empresa vende. $\mathrm{O}$ outro grupo consiste em realizar ações para que o cliente se interesse pela empresa, via marketing de conteúdo e posteriormente realizando ações de anúncios para que o conteúdo chegue às pessoas. Pode ser utilizada segmentação de público-alvo para uma efetividade das ações e, a partir daí, o consumidor irá lembrar-se da empresa quando precisar de um produto que ela comercializa.

Nesta visão, estas ações abordam mais o conceito de publicidade da marca do que uma influenciadora de decisão imediata de compra, pois para vender, o cliente quando reconhece a sua necessidade, ele busca as melhores opções, conforme retratado no processo decisório de compra de Hawking e Mothersbaugh (2019). 


\section{Considerações Finais}

A presente pesquisa teve como objetivo descrever as estratégias de marketing digital utilizadas pelas empresas do varejo de vestuário de Cuiabá-MT e o perfil e comportamento dos consumidores desta região, destacando também os fatores que influenciam no processo decisório da compra. Assim, foi possível atingir o objetivo pretendido na pesquisa.

O estudo demonstrou que o perfil socioeconômico dos participantes da pesquisa considerados consumidores de varejo de vestuário de Cuiabá é formado por grande parte de mulheres, a idade de 19 a 29 anos, em sua maioria, solteiros, com nível de escolaridade de graduação e pós-graduação, a maioria possui renda de até $\mathrm{R} \$ 3.000,00$.

No que diz respeito ao comportamento de consumo, alegam que a compra é realizada predominantemente em loja física, realizando suas compras na maioria a cada 2 ou 3 meses, sendo a decisão mais ou menos planejada. Quanto ao acesso às redes sociais, as que são mais acessadas são Instagram e Facebook e os consumidores estão conectados diariamente entre 1 a 6 horas.

Quanto às estratégias utilizadas pelas empresas, percebeu-se que as duas reconhecem a importância do marketing digital para aumentar o número de clientes, relacionamento e futuras vendas. Contudo, apenas uma delas trabalha fortemente com o marketing digital, uma vez que vende somente por e-commerce, reconhecendo a importância dos investimentos no marketing digital.

Nos resultados, destaca-se que variáveis presentes nas ações de marketing digital tiveram pouca importância na visão dos participantes da pesquisa - grupo dos consumidores, mesmo que estes alegaram estar grande parte do dia conectado em uma rede social. Entretanto, as empresas reconhecem a importância do marketing digital em seu negócio. Para tanto, com vistas à utilização efetiva do marketing digital, as empresas podem desenvolver ações para se tornarem visíveis nos ambientes virtuais de modo que seus clientes as encontrem e possam adquirir seus produtos e/ou interagir com as empresas e outros consumidores.

Quanto às limitações observadas, essas dizem respeito às demais vertentes que poderiam ter sido acrescentadas, como a questão de fontes de pesquisa antes de efetuar uma compra, para promover uma investigação mais a fundo, gerando informações mais precisas sobre as influências e o caminho deste novo consumidor na Internet. Cabe ressaltar ainda o tamanho da amostra e a escolha não probabilística, sugerindo para estudos futuros uma apuração em amostra maior, em outras cidades, destacando as estratégias das empresas com as influências percebidas pelos consumidores, para comparar com o resultado alcançado nesta pesquisa.

Por fim, observa-se a contribuição do presente estudo, pois permite que as empresas do ramo de vestuário conheçam o comportamento de compra destes consumidores, bem como seu perfil socioeconômico, conhecendo também as principais influências que fomentam seu consumo. Além disso, é possível que as empresas utilizem esses dados e análises desta pesquisa para planejar novas ações utilizando segmentação.

Em relação às contribuições aos consumidores, estes se beneficiam por terem acesso a informações das empresas para adquirir produtos melhores e ter eficiência no acesso às informações. Em termos de contribuições à academia, amplia as pesquisas nesta área, especialmente sobre marketing digital e comportamento do consumidor. 


\section{Referências}

ALMEIDA JUNIOR, A. L. de; SILVA, T. C. da; RODRIGUEZ, M. E.; SANTOS, P. M. C. dos; ALMEIDA, T. M. Marketing digital sua influência no comportamento dos consumidores de produtos/moda na cidade de Cataguases - MG. In: Anais...Congresso Internacional de Linguagem e Tecnologia Online, 9, 2017. Disponível em:<http://evidosol.textolivre.org>, Acesso em 30 de maio de 2019.

BARDIN, L. Análise de Conteúdo. São Paulo: Edições 70, 2011.

BRAGA, G. C.; COELHO, M. de F. Marketing Digital: Estratégias de Blogueiras de Moda. Marketing e Tourism, Belo Horizonte, v.3, n. 2, agosto, 2018.

DIAS, J. P. da S.; HEMAIS, M. W. Consumidores de baixa renda e compras on-line: Receios em consumir pela Internet. Revista de Gestão, São Paulo, v. 22, n1, p. 115132, jan-mar, 2015.

GIL, A. C. Métodos e Técnicas de Pesquisa Social. 7 ed. São Paulo: Atlas, 2019.

HAWKING, D. I.; MOTHERSBAUGH, D. L. Comportamento do Consumidor: construindo a estratégia de marketing.13 ed. Rio de Janeiro: Elsevier, 2019.

IBGE. Instituto Brasileiro de Geografia e Estatística. Acesso à internet e à televisão e posse de telefone móvel celular para uso pessoal 2017. Pnad Contínua. IBGE, 2018. Disponível

em

$\langle\underline{\text { https://biblioteca.ibge.gov.br/visualizacao/livros/liv101631_informativo.pdf }}>$,

acesso em 17 de abril de 2020.

KOTLER, P. KELLER, K. L. Administração de Marketing. Trad. Sônia Midori Yamamoto. Revisão técnica Edson Crescitelli. 14. ed. São Paulo: Pearson Education do Brasil, 2012.

KOTLER, P.; KARTAJAYA, H.; SETIAWAN, I. Marketing 3.0: as forças que estão definindo o novo marketing centrado no ser humano. Trad. Ana Beatriz Rodrigues. Rio de Janeiro: Elsevier, 2012.

KOTLER, P.; KARTAJAYA, H.; SETIAWAN, I. Marketing 4.0. Trad. Ivo Korytowski. Rio de Janeiro: Sextante, 2017.

LAKATOS, E. M.; MARCONI, M. de A. Fundamentos de metodologia científica. 5 ed. São Paulo: Atlas, 2003.

MACHADO, C. de M. N.;CAMFIELD, C. E. R.; CIPOLAT, C.; QUADROS, J. do N. de. Os 4 P's do Marketing: Uma análise em uma Empresa Familiar do ramo de serviços do norte do Rio Grande do Sul. In: Simpósio de Excelência em Gestão e Tecnologia, 9, 2012, Resende-RJ. Anais [...]. Resende: Associação Educacional Dom Bosco, 2012, p. $1-16$.

MADAlOSSO, B.; GONÇALVES, R. B., PICCIN, T. As redes sociais e a gestão de relacionamento em vinícolas: Um estudo de múltiplos casos. Revista Geintec, São Cristóvão, v. 6, n. 1, p. 2718-2733, 2016.

MATTAR, F. N. Administração de varejo. Rio de Janeiro: Elsevier, 2011.

MORESI, E. Metodologia de Pesquisa. Universidade Católica de Brasilia, Brasillia, 2003. 
OlIVEIRA, T. P. P. de; SARAIVA, P. M. A Influência do Marketing Digital no Perfil de Consumo da Geração Y. Revista Multidisciplinar e de Psicologia, v. 13, n. 44, p. 589-600, 2019.

POIO, G. M.; TRIGUEIRO, F. M. C.; LEITE, D. B. Fatores que influenciam a escolha de marcas e o comportamento de compra de consumidores do segmento de moda em Cuiabá - MT: Similaridades e Diferenças entre Gêneros. Revista Estudos e Pesquisas em Administração, v. 2, n. 1, p. 84-103, 2018.

PRODANOV, C. C.; FREITAS, E. C. de. Metodologia do trabalho científico: métodos e técnicas da pesquisa e do trabalho acadêmico. 2 ed. Novo Hamburgo: Feevale, 2013.

SAMARA, B. S.; MORSCH, M. A. Comportamento do consumidor: conceitos e casos. São Paulo: Prentice Hall, 2005.

SILVA, F. W. A. da; LIMA, P. F. de; LIMA, M. M. L. Marketing Digital como Estratégia Competitiva dentro das Organizações: Um Estudo de Caso em uma Rede Empresarial na Região do Cariri - CE. Revista Multidisciplinar e de Psicologia, v. 12, n. 42, p.85-108, 2018.

SOCIEDADE BRASILEIRA DE VAREJO E CONSUMO. Estudo revela importante papel do varejo na economia brasileira. 2018a. Disponível em: <http//sbvc.com.br/estudo-papel-varejo-2018/> Acesso em: 17 de junho de 2019.

SOCIEDADE BRASILEIRA DE VAREJO E CONSUMO. Os Novos Consumidores Brasileiros: Hábitos de compra e consumo dos jovens entre 16 e 22 anos. 2018b. Disponível em: $<\mathrm{http} / / \mathrm{sbvc.com} \cdot \mathrm{br} / \mathrm{wp}-$ content/uploads/2018/08/Pesquisa_SBVC_AGP_Novos_Consumidores.pdf $>$ Acesso em: 23 de junho de 2019.

SOUZA, M.; SERRENTINO, A. Multivarejo na próxima economia. São Paulo: Pearson Education do Brasil, 2002.

STEINHORST, J. G.; CARMO, E. R. do; MIORANZA, C. Aplicação da metodologia dos 8Ps do Marketing Digital em uma indústria metalúrgica. In: Conferência Internacional em Gestão de Negócios, 1, 2015, Cascavel-PR. Anais [...]. Cascavel: UNIOESTE, 2015, p. 1-16.

TORRES, C. A Bíblia do marketing digital: tudo o que você queria saber sobre marketing e publicidade na Internet e não tinha a quem perguntar. São Paulo: Novatec, 2009.

VAZ, C. A. Os 8Ps do marketing digital: o guia estratégico de marketing digital. São Paulo: Novatec, 2011.

VERGARA, S. C. Projetos e relatórios de pesquisa em administração. 16 ed. São Paulo: Atlas, 2016. 